\title{
REPRESENTASI KANONIK UNTUK FUNGSI KARAKTERISTIK DARI SEBARAN TERBAGI TAK HINGGA
}

\author{
EKA RAHMI KAHAR, DODI DEVIANTO \\ Program Studi Matematika, \\ Fakultas Matematika dan Ilmu Pengetahuan Alam, Universitas Andalas, \\ Kampus UNAND Limau Manis Padang, Indonesia, \\ eicha.rhahmi@yahoo.com
}

\begin{abstract}
Abstrak. Fungsi karakteristik dari sebaran terbagi tak hingga dapat dikarakterisasi ke dalam suatu formula umum yang disebut sebagai representasi kanonik fungsi karakteristik sebaran terbagi tak hingga. Representasi kanonik tersebut dapat dilakukan dengan menentukan ukuran Levy dari sebaran yang bersesuaian. Sebaran Normal dan Sebaran Eksponensial merupakan sebaran terbagi tak hingga sehingga dapat dibentuk representasi kanonik fungsi karakteristiknya.

Kata Kunci: Representasi kanonik fungsi karakteristik, sebaran terbagi tak hingga, sebaran normal, sebaran eksponensial
\end{abstract}

\section{Pendahuluan}

Keterbagian tak hingga suatu sebaran dapat ditentukan melalui peubah acaknya atau fungsi karakteristiknya. Keterbagian tak hingga berdasarkan peubah acak dapat dilihat sebagai keterbagian suatu peubah acak menjadi peubah-peubah acak yang saling bebas dengan sebaran yang sama. Peubah acak $X$ dikatakan terbagi menjadi $n$ jika terdapat peubah-peubah acak yang identik dan saling bebas $X_{1}, X_{2}, \cdots, X_{n}$ sedemikian sehingga $X=X_{1}+X_{2}+\cdots+X_{n}$. Selanjutnya, suatu fungsi sebaran $\mathrm{F}$ dengan fungsi karakteristik $\varphi$ adalah terbagi tak hingga jika untuk setiap bilangan bulat positif $n$ terdapat fungsi karakteristik $\varphi_{n}$ sedemikian sehingga $\varphi(t)=\left[\varphi_{n}(t)\right]^{n}$ untuk setiap $t \in \mathbb{R}[4]$. Fungsi karakteristik dari sebaran terbagi tak hingga dapat dikarakterisasi ke dalam suatu formula umum yang disebut sebagai representasi kanonik fungsi karakteristik sebaran terbagi tak hingga.

Pengkarakterisasian fungsi karakteristik sebaran terbagi tak hingga diusulkan pertama kali oleh Bruno de Finetti (1929), yang kemudian dilanjutkan oleh Kolmogorov (1932) untuk kasus momen kedua terbatas dan kemudian diturunkan oleh Levy-Khinchine (1937) sehingga menghasilkan suatu formula umum yang disebut Representasi kanonik fungsi karakteristik sebaran terbagi tak hingga [3,6]. Paper ini memberikan kajian representasi kanonik fungsi karakteristik untuk sebaran terbagi tak hingga serta penggunaannya pada keterbagian tak hingga Sebaran Normal dan Sebaran Eksponensial. 


\section{Sebaran Terbagi Tak Hingga}

Berikut ini akan dibahas mengenai definisi dan teorema dari fungsi sebaran terbagi tak hingga.

Definisi 2.1. [7] Suatu fungsi sebaran $F$ dikatakan terbagi tak hingga jika untuk setiap bilangan bulat positif $n$, terdapat suatu fungsi sebaran $F_{n}$ sedemikian sehingga $F$ adalah konvolusi $n$ kali dari $F_{n}$ dengan dirinya sendiri, yaitu $F=F_{n} * \cdots * F_{n}$ ( $n$ kali).

Selain itu keterbagian tak hingga dapat dilihat berdasarkan fungsi karaktiristiknya. Berikut diberikan definisi dari fungsi karakteristik kemudian dilanjutkan dengan definisi sebaran terbagi tak hingga berdasarkan fungsi karakteristik.

Definisi 2.2. [1,2] Jika $X$ suatu peubah acak dengan fungsi kepekatan peluang $f(x)$ dan fungsi sebaran kumulatif $F(x)$, maka fungsi karakteristik $\varphi_{X}(t)$ dari peubah acak $X$ didefinisikan sebagai berikut

$$
\varphi_{X}(t)=E\left[e^{i t X}\right]=\int e^{i t x} d F(x),
$$

dimana $t \in \mathbb{R}, i=\sqrt{-1}$ dan $e^{i t X}=\cos t X+i \sin t X$.

Berdasarkan definisi fungsi karakteristiknya, suatu fungsi sebaran $F$ dengan fungsi karakteristik $\varphi$ adalah terbagi tak hingga jika untuk setiap bilangan bulat positif $n$ terdapat fungsi karakteristik $\varphi_{n}$ sedemikian sehingga $\varphi(t)=\left[\varphi_{n}(t)\right]^{n}$ untuk setiap $t[2]$.

\section{Representasi Kanonik Fungsi Karakteristik Sebaran Terbagi Tak Hingga}

Berikut diberikan lema dan teorema mengenai representasi kanonik dari fungsi karakteristik sebaran terbagi tak hingga.

Lema 3.1. [5] Misalkan $\varphi(t)$ adalah suatu fungsi karakteristik terbagi tak hingga. Maka terdapat suatu barisan dari fungsi $\phi_{n}(t)$ sedemikian sehingga

$$
\lim _{n \rightarrow \infty} \phi_{n}(t)=\phi(t)=\ln \varphi(t) .
$$

Bukti. Karena untuk $n \rightarrow \infty$,

$n\left([\varphi(t)]^{\frac{1}{n}}-1\right)=n\left(\exp \left[\left(\frac{1}{n}\right) \phi(t)\right]-1\right)=\phi(t)+\left(\frac{1}{n}\right) \frac{(\phi(t))^{2}}{2 !}+\left(\frac{1}{n}\right)^{2} \frac{(\phi(t))^{3}}{3 !}+\cdots$,

maka diperoleh

$$
\phi(t)=\lim _{n \rightarrow \infty} n\left([\varphi(t)]^{\frac{1}{n}}-1\right) .
$$

Berdasarkan asumsi, $\varphi(t)$ adalah fungsi karakteristik terbagi tak hingga, maka $[\varphi(t)]^{\frac{1}{n}}$ merupakan suatu fungsi karakteristik. Misal dinotasikan fungsi sebaran yang 
bersesuaian adalah $F_{n}(x)$, maka

$$
n\left([\varphi(t)]^{\frac{1}{n}}-1\right)=n i t \int_{-\infty}^{\infty} \frac{x}{1+x^{2}} d F_{n}(x)+n \int_{-\infty}^{\infty}\left(e^{i t x}-1-\frac{i t x}{1+x^{2}}\right) d F_{n}(x),
$$

Misalkan ditulis,

$$
\begin{array}{r}
\gamma_{n}=n \int_{-\infty}^{\infty} \frac{x}{1+x^{2}} d F_{n}(x), \quad \beta_{n}(x)=n \int_{-\infty}^{x} \frac{y^{2}}{1+y^{2}} d F_{n}(y) \\
\phi_{n}(t)=\gamma_{n} i t+\int_{-\infty}^{\infty}\left(e^{i t x}-1-\frac{i t x}{1+x^{2}}\right) \frac{1+x^{2}}{x^{2}} d \beta_{n}(x)
\end{array}
$$

maka dari $(3.2)$ - (3.4) terbukti bahwa terdapat $\phi_{n}(t)$ sedemikian sehingga

$$
\lim _{n \rightarrow \infty} \phi_{n}(t)=\phi(t)=\ln \varphi(t) .
$$

Lema 3.2. [n] Jika $A(x, t)$ didefinisikan untuk $x \in(-\infty, 0) \cup(0, \infty)$ dan $t \in$ $(-\infty,+\infty)$ dengan

$$
A(x, t)=\left(e^{i t x}-1-\frac{i t x}{1+x^{2}}\right) \frac{1+x^{2}}{x^{2}}
$$

maka $\lim _{x \rightarrow 0} A(x, t)=\frac{-t^{2}}{2}$.

Bukti. Lema ini dapat dibuktikan dengan menggunakan

$$
e^{i t x}=1+i t x+\frac{(i t x)^{2}}{2 !}+\frac{(i t x)^{3}}{3 !}+\cdots
$$

Teorema 3.3. [7] (Representasi Kanonik Levy-Khinchine) Suatu fungsi $\varphi$ adalah fungsi karakteristik dari suatu fungsi sebaran terbagi tak hingga jika dan hanya jika terdapat suatu bilangan real $\gamma$ dan fungsi takturun terbatas $\beta$ yang terdefinisi pada $(-\infty,+\infty)$ sedemikian sehingga

$$
\varphi(t)=\exp \left[i \gamma t+\int_{-\infty}^{\infty}\left(\exp [i t x]-1-\frac{i t x}{1+x^{2}}\right) \frac{1+x^{2}}{x^{2}} d \beta(x)\right]
$$

dimana integran terdefinisi pada $x=0$ dengan kontinuitas menjadi $\frac{-t^{2}}{2}$. Representasi kanonik pasangan $(\gamma, \beta)$ ini tunggal.

Bukti. $(\Rightarrow)$ Misalkan $\varphi$ adalah fungsi karakteristik dari suatu fungsi sebaran terbagi tak hingga. Akan ditunjukkan terdapat suatu bilangan real $\gamma$ dan fungsi takturun terbatas $\beta$ yang terdefinisi pada $(-\infty,+\infty)$ sedemikian sehingga

$$
\varphi(t)=\exp \left[i \gamma t+\int_{-\infty}^{\infty}\left(\exp [i t x]-1-\frac{i t x}{1+x^{2}}\right) \frac{1+x^{2}}{x^{2}} d \beta(x)\right],
$$

dimana integran terdefinisi pada $x=0$ dengan kontinuitas menjadi $\frac{-t^{2}}{2}$.

Misalkan $F_{n}$ adalah fungsi sebaran yang bersesuaian dengan fungsi karakteristik $\varphi_{n}$, dimana $\left[\varphi_{n}(t)\right]^{n}=\varphi(t)$ untuk setiap bilangan bulat positif $n$ dan misalkan ditulis

$$
\beta_{n}(t)=n \int_{-\infty}^{t} \frac{x^{2}}{1+x^{2}} d F_{n}(x) \text { dan } I_{n}(t)=\int_{-\infty}^{\infty}\left(e^{i t x}-1\right) \frac{1+x^{2}}{x^{2}} d \beta_{n}(x) .
$$


Maka dengan menggunakan Lema 3.1 diperoleh $\lim _{n \rightarrow \infty} I_{n}(t)=\ln \varphi(t)$. Kemudian, jika "bagian rill" dinotasikan dengan Re, maka

$$
\lim _{n \rightarrow \infty} \operatorname{Re} I_{n}(t)=\lim _{n \rightarrow \infty} \int_{-\infty}^{\infty}(\cos (t x)-1) \frac{1+x^{2}}{x^{2}} d \beta_{n}(x)=\ln |\varphi(t)| .
$$

Karena $\beta_{n}(-\infty)=0$ dan dengan menggunakan persamaan (3.7), diperoleh bahwa $\beta_{n}$ terbatas dan $\int_{|x|>T} d \beta_{n}(x)<\varepsilon$. Sehingga terdapat subbarisan dari $\left\{\beta_{n}\right\}$ yang konvergen lengkap. Misal subbarisan tersebut adalah $\left\{\beta_{n_{k}}\right\}$ dan misalkan terdapat suatu fungsi tak turun terbatas $\beta$ sedemikian sehingga $\beta_{n_{k}} \stackrel{c}{\rightarrow} \beta$. Untuk $t$ tertentu, $A(x, t)$ seperti yang didefinisikan pada Lema 3.2 adalah fungsi kontinu terbatas pada $x$. Sehingga

$$
\int_{-\infty}^{\infty} A(x, t) d \beta_{n_{k}}(x) \rightarrow \int_{-\infty}^{\infty} A(x, t) d \beta(x), \quad k \rightarrow \infty .
$$

Misalkan ditulis

$$
\gamma_{n_{k}}=\int_{-\infty}^{\infty} \frac{1}{x} d \beta_{n_{k}}(x)=n_{k} \int_{-\infty}^{\infty} \frac{x}{1+x^{2}} d F_{n_{k}}(x),
$$

maka diperoleh

$$
I_{n_{k}}(t)=\int_{-\infty}^{\infty} A(x, t) d \beta_{n_{k}}(x)+i t \gamma_{n_{k}} .
$$

Sehingga terdapat bilangan riil $\gamma$ sedemikian sehingga $\gamma_{n_{k}} \rightarrow \gamma$ untuk $k \rightarrow \infty$.

Karena $I_{n_{k}}(t) \rightarrow \ln \varphi(t)$ untuk $k \rightarrow \infty$, maka $\varphi(t)=\exp \left[i \gamma t+\int A(x, t) d \beta_{n}(x)\right]$ yang membuktikan bahwa $\varphi(t)$ dapat direpresentasikan menjadi persamaan (3.5).

$(\Leftarrow)$ Misalkan terdapat suatu bilangan riil $\gamma$ dan fungsi takturun terbatas $\beta$ yang terdefinisi pada $(-\infty,+\infty)$ sedemikian sehingga berlaku persamaan $(3.5)$, dimana integran terdefinisi pada $x=0$ dengan kontinuitas menjadi $\frac{-t^{2}}{2}$. Akan ditunjukkan bahwa $\varphi$ fungsi karakteristik dari suatu fungsi sebaran terbagi tak hingga.

Perhatikan dua kasus berikut:

Kasus 1. Misalkan $0<\lambda=\int_{-\infty}^{-0}+\int_{+0}^{\infty} \frac{1+x^{2}}{x^{2}} d \beta(x)<\infty, I=(-\infty, 0) \cup(0, \infty)$, $H(x)=\frac{1}{\lambda} \int_{I \cap(-\infty, x)} \frac{1+x^{2}}{x^{2}} d \beta(x)$, dan $\sigma^{2}=\beta(+0)-\beta(-0)$. Maka $H$ adalah fungsi sebaran, dan jika $h(t)$ adalah fungsi karakteristik dari fungsi sebaran H, maka

$$
\varphi(t)=\exp \left[i \gamma^{\prime} t-\frac{\sigma^{2} t^{2}}{2}+\lambda(h(t)-1)\right],
$$

dimana $\gamma^{\prime}=\gamma-\int_{I}\left(\frac{1}{x}\right) d \beta(x)$. Hal ini menunjukkan bahwa $\varphi(t)$ adalah suatu fungsi karakteristik dari sebaran terbagi tak hingga.

Pada kasus $\lambda=0, \sigma^{2}>0$, maka $\varphi(t)$ adalah fungsi karakteristik dari sebaran $N\left(\gamma^{\prime}, \sigma^{2}\right)$ yang menunjukkan bahwa $\varphi(t)$ adalah suatu fungsi karakteristik dari sebaran terbagi tak hingga.

Kasus 2. Misalkan $\int_{I}\left(\frac{1+x^{2}}{x^{2}}\right) d \beta(x)=\infty$, dan misalkan $\left\{x_{n}\right\}$ adalah suatu barisan bilangan positif sedemikian sehingga $x_{n}>x_{n+1}$ untuk semua $n$ dan $x_{n} \rightarrow 0$ untuk $n \rightarrow \infty$.

Misalkan ditulis $A_{1}=\left(-\infty,-x_{1}\right] \cup\left[x_{1}, \infty\right)$ dan $A_{n}=\left(-x_{n-1},-x_{n}\right] \cup\left[x_{n}, x_{n-1}\right)$, untuk $n=2,3, \cdots$ dan sehingga dapat didefinisikan $\lambda_{n}=\int_{A_{n}} \frac{1+x^{2}}{x^{2}} d \beta(x)>0$, untuk setiap n. 
Perhatikan bahwa $(-\infty, 0) \cup(0, \infty)=I=\bigcup_{n=1}^{\infty} A_{n}$. Misalkan

$$
F_{n}(x)=\lambda_{n}^{-1} \int_{A_{n} \cap(-\infty, x]} \frac{1+x^{2}}{x^{2}} d \beta(x),
$$

maka jelas bahwa $F_{n}$ suatu fungsi sebaran.

Misalkan $\left\{Z, X_{n, j}, Y_{n}, n=1,2, \cdots, j=1,2, \cdots\right\}$ adalah peubah acak saling bebas sedemikian sehingga $Z$ adalah peubah acak dari sebaran $N\left(0, \sigma^{2}\right)$, fungsi sebaran dari peubah acak $X_{n, j}$ adalah $F_{n}$, dan $Y_{n}$ adalah peubah acak Poisson dengan $E\left[Y_{n}\right]=\lambda_{n}$.

Misalkan

$$
X_{n}=(\gamma+Z)+\left(\sum_{m=1}^{n}\left(X_{m, 1}+\cdots+X_{m, y_{m}}\right)-\sum_{m=1}^{n} \int_{A_{m}}\left(\frac{1}{x}\right) d \beta(x)\right),
$$

maka dengan memisalkan $\varphi_{X_{n, j}}$ adalah fungsi karakteristik dari peubah acak $X_{n, j}$, diperoleh fungsi karakteristik dari peubah $\left\{X_{n}\right\}$ sebagai berikut

$$
\varphi_{n}(t)=\exp \left[i \gamma t-\frac{\sigma^{2} t^{2}}{2}+\int_{-\infty}^{-x_{n}}+\int_{x_{n}}^{\infty} A(x, t) d \beta(x)\right]
$$

dengan $A(x, u)$ seperti yang didefinisikan pada Lema 3.2. Sehingga jelas bahwa $\varphi_{n}(t)$ merupakan fungsi karakteristik dari sebaran terbagi tak hingga dan $\varphi_{n}(t) \rightarrow$ $\varphi(t)$ untuk $n \rightarrow \infty$ pada semua $t$. Oleh karena itu, diperoleh bahwa $\varphi(t)$ adalah fungsi karakteristik dari sebaran $F$ dan $F_{n} \stackrel{c}{\rightarrow} F$, sehingga fungsi sebaran $F$ terbagi tak hingga yang membuktikan bahwa $\varphi(t)$ adalah fungsi karakteristik dari suatu fungsi sebaran terbagi tak hingga.

Selanjutnya akan ditunjukkan representasi kanonik pasangan $(\gamma, \beta)$ diatas tunggal, yaitu cukup dengan menunjukkan ketunggalan dari $\beta$. Misalkan ditulis

$$
-\phi(t)=\int_{t-1}^{t+1} \ln \varphi(\tau) d \tau-2 \ln \varphi(t)
$$

Maka jelas bahwa $\varphi$ secara tunggal menentukan $\phi$ dan diperoleh

$$
\phi(t)=2 \int_{-\infty}^{\infty} \exp (i t x)\left(1-\frac{\sin x}{x}\right) \frac{1+x^{2}}{x^{2}} d \beta(x) .
$$

Karena $\left(1-\frac{\sin x}{x}\right) \frac{1+x^{2}}{x^{2}}>0$ untuk setiap $x$, maka jika didefinisikan

$$
\Phi(x)=2 \int_{-\infty}^{x}\left(1-\frac{\sin y}{y}\right) \frac{1+y^{2}}{y^{2}} d \beta(y),
$$

diperoleh

$$
\phi(u)=\int_{-\infty}^{\infty} \exp (i t x) d \Phi(x) .
$$

(Catatan : $\Phi$ adalah fungsi takturun karena $\Phi$ merupakan integral dari fungsi tak negatif).

Karena integral yang menfinisikan $\Phi$ adalah positif, maka $\Phi$ secara tunggal menentukan $\beta$. Sehingga $\varphi$ secara tunggal menentukan $\beta$ dan $\gamma$. 
Teorema 3.4. [7] (Representasi Kanonik Levy) Suatu fungsi f adalah fungsi karakteristik dari suatu fungsi sebaran terbagi tak hingga jika dan hanya jika terdapat konstanta $\gamma$ dan fungsi $M$ yang terdefinisi pada $(-\infty, 0) \cup(0, \infty)$ yang tak turun pada $(-\infty, 0)$ dan $(0, \infty)$ dan memenuhi $M(-\infty)=M(\infty)=0$ dan

$$
\int_{-1}^{-0}+\int_{+0}^{+1} x^{2} d M(x)<\infty
$$

sedemikian sehingga

$$
\varphi(t)=\exp \left[i \gamma t-\frac{\sigma^{2} t^{2}}{2}+\int_{-\infty}^{-0}+\int_{+0}^{+\infty}\left(\exp [i t x]-1-\frac{i t x}{1+x^{2}}\right) d M(x)\right] .
$$

Representasi kanonik tripel $\left(\gamma, \sigma^{2}, M\right)$ ini tunggal.

Teorema Representasi Levy jelas ekuivalen dengan Teorema Representasi LevyKhinchine dengan menggunakan hubungan

$$
M(x)=\left\{\begin{array}{c}
-\int_{x}^{\infty} \frac{1+y^{2}}{y^{2}} d \beta(y), \text { untuk } x>0 \\
\int_{\infty}^{x} \frac{1+y^{2}}{y^{2}} d \beta(y), \text { untuk } x<0
\end{array}\right.
$$

Formula (3.9) di atas disebut sebagai Representasi Kanonik Levy dari $\varphi(t)$, dimana $M(x)$ disebut sebagai ukuran Levy.

\section{Representasi Kanonik Fungsi Karakteristik Sebaran Normal dan Sebaran Eksponensial}

\subsection{Sebaran Normal}

Misalkan $X \sim N\left(\mu, \sigma^{2}\right)$ dengan fungsi kepekatan peluang

$$
f(x)=\frac{1}{\sqrt{2 \pi \sigma^{2}}} \exp \left[-\frac{(x-\mu)^{2}}{2 \sigma^{2}}\right], \text { untuk }-\infty<x<\infty,
$$

dimana $\mu$ dan $\sigma^{2}$ adalah konstanta, $-\infty<\mu<\infty, \sigma^{2}>0$. Maka fungsi karakteristiknya adalah $\varphi(t)=\exp \left(i \mu t-\frac{\sigma^{2} t^{2}}{2}\right)$. Karena untuk sebarang bilangan bulat $n$, terdapat $\varphi_{n}(t)=\exp \left[\frac{i \mu t}{n}-\frac{\sigma^{2} t^{2}}{2 n}\right]$ yaitu fungsi karakteristik dari sebaran $N\left(\frac{\mu}{n}, \frac{\sigma^{2}}{n}\right)$ sedemikian sehingga berlaku $\varphi(t)=\left[\varphi_{n}(t)\right]^{n}$, maka Sebaran Normal merupakan sebaran terbagi tak hingga. Perhatikan bahwa fungsi karakteristik Sebaran Normal di atas dapat ditulis sebagai berikut

$$
\varphi(t)=\exp \left(i \mu t-\frac{\sigma^{2} t^{2}}{2}+\int_{-\infty}^{-0}+\int_{+0}^{+\infty}\left(\exp [i t x]-1-\frac{i t x}{1+x^{2}}\right) d[0]\right) .
$$

Sehingga fungsi karakteristik Sebaran Normal dapat dibentuk ke dalam Representasi Kanonik Levy dengan $\gamma=\mu, \sigma^{2}=\sigma^{2}$, dan $M(x)=0$.

\subsection{Sebaran Eksponensial}

Misalkan $X \sim \exp (\theta)$ dengan fungsi kepekatan peluang

$$
f(x)=\frac{1}{\theta} e^{-x / \theta}, \quad x>0
$$


Maka fungsi krakteristiknya adalah

$$
\varphi(t)=E\left[e^{i t X}\right]=\int_{0}^{\infty} e^{i t x} \frac{1}{\theta} e^{-\frac{x}{\theta}} d x=\frac{1}{1-i t \theta} .
$$

Karena untuk sebarang bilangan bulat $n$, terdapat $\varphi_{n}(t)=\left(\frac{1}{(1-i t \theta)}\right)^{\frac{1}{n}}$ yaitu fungsi karakteristik dari sebaran $\operatorname{GAM}\left(\theta, \frac{1}{n}\right)$ sedemikian sehingga berlaku $\varphi(t)=\left[\varphi_{n}(t)\right]^{n}$, maka sebaran Eksponensial merupakan sebaran terbagi tak hingga.

Perhatikan bahwa $\varphi_{n}(t)$ merupakan fungsi karakteristik dari $\operatorname{GAM}\left(\theta, \frac{1}{n}\right)$, maka fungsi sebaran yang bersesuaian untuk fungsi karakteristik tersebut adalah

$$
F_{n}(x)=\frac{1}{\theta^{1 / n} \Gamma(1 / n)} \int_{0}^{x} y^{\frac{1}{n}-1} e^{-y / \theta} d y
$$

Selanjutnya, dengan menggunakan $\beta$ dan $\gamma$ yang telah diperoleh pada pembuktian Lema 3.1 dan Teorema 3.3, maka fungsi karakteristik sebaran Eksponensial dapat dibentuk ke dalam Representasi Kanonik Levy-Khinchine dengan

$$
\gamma=\lim _{n \rightarrow \infty} \gamma_{n}=\lim _{n \rightarrow \infty} n \int_{-\infty}^{\infty} \frac{x}{1+x^{2}} d F_{n}(x)=\int_{0}^{\infty} \frac{e^{-x / \theta}}{1+x^{2}} d x
$$

dan

$$
\beta(x)=\lim _{n \rightarrow \infty} \beta_{n}(x)=\lim _{n \rightarrow \infty} n \int_{-\infty}^{x} \frac{y^{2}}{1+y^{2}} d F_{n}(y)=\int_{0}^{x} \frac{y}{1+y^{2}} e^{-y / \theta} d y, \quad x>0 .
$$

Kemudian, dengan menggunakan hubungan Representasi Kanonik Levy dan Representasi Kanonik Levy-Khinchine, perhatikan bahwa

$$
\begin{array}{rlrl}
M(x) & =-\int_{x}^{\infty} \frac{1+y^{2}}{y^{2}} d \beta(y)=-\int_{x}^{\infty} \frac{1+y^{2}}{y^{2}} d\left(\int_{0}^{y} \frac{x}{1+x^{2}} e^{-x / \theta} d x\right) \\
& =-\int_{x}^{\infty} \frac{e^{-y / \theta}}{y} d y & , x>0 .
\end{array}
$$

Sehingga fungsi karakteristik dari sebaran Eksponensial dapat dibentuk ke dalam Representasi Kanonik Levy dengan $\gamma=\int_{0}^{\infty} \frac{e^{-x / \theta}}{1+x^{2}} d x, \sigma^{2}=0$, dan $M(x)=$ $-\int_{x}^{\infty} \frac{e^{-y / \theta}}{y} d y, \quad x>0$.

\section{Kesimpulan}

Fungsi karakteristik dari sebaran terbagi tak hingga dapat dikarakterisasi ke dalam suatu formula umum yang disebut sebagai representasi kanonik fungsi karakteristik sebaran terbagi tak hingga. Jika suatu peubah acak $X$ merupakan suatu sebaran terbagi tak hingga, bentuk representasi kanonik untuk fungsi karakteristik dari sebaran $X$ adalah

$$
\varphi(t)=\exp \left[i \gamma t+\int_{-\infty}^{\infty}\left(\exp [i t x]-1-\frac{i t x}{1+x^{2}}\right) \frac{1+x^{2}}{x^{2}} d \beta(x)\right],
$$

dimana representasi kanonik pasangan $(\gamma, \beta)$ tersebut tunggal. Representasi kanonik diatas dinamakan Representasi Kanonik Levy-Khinchine. Selain Representasi 
Kanonik Levy-Khinchine terdapat bentuk representasi kanonik yang lain dari sebaran tebagi tak hingga, yaitu disebut dengan Representasi Kanonik Levy. Bentuk Representasi Kanonik Levy untuk fungsi karakteristik dari sebaran terbagi tak hingga adalah sebagai berikut

$$
\varphi(t)=\exp \left[i \gamma t-\frac{\sigma^{2} t^{2}}{2}+\int_{-\infty}^{-0}+\int_{+0}^{+\infty}\left(\exp [i t x]-1-\frac{i t x}{1+x^{2}}\right) d M(x)\right] .
$$

dimana Representasi Kanonik Levy ini ekivalen dengan Representasi Kanonik LevyKhinchine, yaitu dengan menggunakan hubungan

$$
M(x)=\left\{\begin{array}{c}
-\int_{x}^{\infty} \frac{1+y^{2}}{y^{2}} d \beta(y), \text { untuk } x>0 \\
\int_{\infty}^{x} \frac{1+y^{2}}{y^{2}} d \beta(y), \text { untuk } x>0
\end{array}\right.
$$

Representasi kanonik tripel $\left(\gamma, \sigma^{2}, M\right)$ di atas juga tunggal.

Sebaran normal dan sebaran eksponensial adalah sebaran terbagi tak hingga dimana fungsi karakteristiknya dapat dibentuk kedalam Representasi Kanonik Levy. Sebaran normal mempunyai representasi Kanonik Levy dengan $\gamma=\mu, \sigma^{2}=\sigma^{2}$, dan $M(x)=0$. Sementara itu, sebaran eksponensial mempunyai representasi Kanonik Levy dengan $\gamma=\int_{0}^{\infty} \frac{e^{-x / \theta}}{1+x^{2}} d x, \sigma^{2}=0$, dan $M(x)=-\int_{x}^{\infty} \frac{e^{-y / \theta}}{y} d y, \quad x>0$.

\section{Daftar Pustaka}

[1] Bartle, R.G. dan Donald R.S. 1927. Introduction to Real Analysis, Second Edition. John Wiley and Sons. Singapore: Inc

[2] Chung, K. L. 2001. A Course In Probability Theory, Third Edition. San Diego: Academy Press

[3] Gnedenko, B. V. dan A. N. Kolmogorov. 1968. Limit Distributions for Syms of Independent Random Variables. London: Addison-Wiley

[4] Laha, R. G. Dan V. K. Rohagi. 1979. Probability Theory. New York: John Wiley Sons

[5] Lukacs, E. 1970. Characteristic Function, Second Edition. London: Grifin

[6] Rao, M. M. dan R.J. Swift. 2006. Probability Theory with Aplications, Second Edition. United States: Springer

[7] Tucker, H. G. 1967. Probability and Mathematical Statistics. London: Akademic Press 